\title{
Fugas y jugas: alianzas sónicas en un baile-música-performance de la gente negra del sur del valle del río Cauca (Colombia)
}

\author{
Fugas and jugas: sonic alliances in a dance-music-performance \\ of the southern Cauca river valley (Colombia)
}

\author{
Paloma Palau Valderrama* \\ Universidade Federal do Rio Grande do Sul, Brasil
}

DOI: $10.22380 / 2539472 X .1149$

\begin{abstract}
RESUMEN
En el presente artículo analizo cómo se agencian los significados y las disputas en las fugas o jugas, una expresión que oscila entre un ritual afrocatólico y un baile-música de la gente negra que habita el sur del valle geográfico del río Cauca (Colombia). Sostengo que las fugas/jugas están basadas en una epistemología y una ontología que articulan políticas-saberes-afectos que construyen lo que denomino alianzas sónicas, las cuales invitan a la participación más allá de fronteras étnico-raciales y humanas para la expansión del mundo, en performances donde se traban luchas y negociaciones cosmopolíticas. Parto de mi experiencia etnográfica desde el campo interdisciplinar de las (etno)musicologías, en diálogo con la antropología de la danza, la antropología de la performance y los estudios afrodiaspóricos.
\end{abstract}

Palabras clave: saberes locales, performance, etnomusicología, antropología de la danza.

\begin{abstract}
In this paper I analyze how meanings and disputes are created by fugas or jugas, an expression that oscillates between an Afro-Catholic ritual and a dance-music of the black people who inhabit the southern geographic valley of the Cauca river (COlombia). I argue that fugas/jugas are based on an epistemology and ontology that articulates politics-knowledge-affects that build what I call sonic alliances, which invite participation beyond ethnic-racial and human borders for the expansion of their world in performances where they engage in cosmopolitical struggles and negotiations. I draw on my ethnographic experience from the interdisciplinary field of (ethno)musicologies, in dialogue with the anthropology of dance, anthropology of performance and African diaspora studies.
\end{abstract}

Keywords: local knowledges, performance, ethnomusicology, anthropology of dance.

palomapalau@gmail.com / https://orcid.org/0000-0003-2832-0762 


\section{Múltiples movimientos bailados, cantados y narrados}

En el presente artículo ${ }^{1}$ indago por los significados de la fuga o juga, una manifestación performática que oscila entre un baile-música y un ritual católico de la gente negra ${ }^{2}$ que habita el sur del valle geográfico del río Cauca en Colombia. Parto de la siguiente cuestión: ¿qué significados y disputas se agencian en las fugas/jugas y cómo ocurren? Me baso en mi experiencia recorriendo la región desde 2004 y en la etnografía que adelanté entre 2016 y 2019 para mi tesis doctoral desde el campo interdisciplinar de las (etno)musicologías³ ${ }^{3}$ en diálogo con la antropología de la danza, la antropología de la performance y los estudios afrodiaspóricos.

La fuga o juga es de difícil aprehensión no solo al intentar conceptualizarla, sino también en su escurridizo movimiento corporal. Se baila con un paso básico, de modo individual, en una fila que crece en caprichosas formas según el rumbo que tome el primer bailarín. Los cantos responsoriales o estróficos se repiten circularmente con un ritmo constante, acompañados por diferentes instrumentaciones actualmente conocidas como violines caucanos y papayeras o bandas de viento. El baile-música de fuga o juga es además la actividad central del ritual afrocatólico de las Adoraciones al Niño Dios en la cosmología local, de modo que incluso, a veces, reemplaza su denominación.

Las fugas o jugas en las Adoraciones se transforman en ciertos momentos en una expresión performática que articula la representación de personas disfrazadas de figuras católicas, bailes, cantos y versos recitados. Entre otras ocasiones religiosas y comunitarias basadas en una reciprocidad colectiva, las fugas/ jugas se tocan, cantan y danzan en eventos que resaltan la afrocolombianidad,

1 Este trabajo se deriva de mi tesis de doctorado en Música (Palau 2020) en el área de concentración Etnomusicología/Musicología, financiada por las becas Capes y CNPq (Brasil) y vinculada al Grupo de Estudos Musicais de la Universidade Federal do Rio Grande do Sul, coordinado por la doctora Maria Elizabeth Lucas.

2 En este texto utilizo los conceptos con prefijo afro- y negrx(s) como sinónimos, dado que, aunque han sido objeto de debate, el grueso de la población en la que se enfoca este estudio, mis interlocutores, los usan para autodenominarse.

3 Con (etno)musicologías me refiero al gran campo interdisciplinar que intenta ir más allá de una definición colonialista y que atribuye a la musicología el estudio de las músicas de Occidente y a la etnomusicología, el estudio de las otras músicas. Algunos autores que desde hace varias décadas han abordado tal discusión son Bohlman (1992), Kidula (2006), Menezes (2014) y Stobart (2008). 
en fiestas familiares y, cada vez más, en diferentes acontecimientos con una apertura hacia nuevos públicos ${ }^{4}$.

Además del sentido religioso de la Adoración al Niño Dios, la ambivalencia en la pronunciación de la efe (f) y la jota (j) en fuga/juga — característica de la fonética de la población afrocolombiana en la región- despliega la discursividad en varios significados señalados por mis interlocutores. Así, se explica la juga como juego y diversión colectiva mediante la experiencia del goce y la creatividad. Otro sentido, en sintonía con la construcción de una identidad étnica, señala que la fuga adquiere su nombre porque las personas esclavizadas en el pasado aprovechaban la fila de baile para fugarse. En este artículo mantendré tal ambivalencia sonora/textual.

El baile es sencillo y abierto a la participación de todas las personas, locales y externas; sin embargo, su aparente facilidad, inclusión y saber colectivo no están libres de tensiones que asoman en su movimiento corporal, sónico y en sus narrativas. En este artículo sostengo que las fugas/jugas están basadas en una epistemología y ontología particulares que construyen lo que denomino alianzas sónicas, movilizadas como estrategia para la pervivencia de la vida colectiva negra y la expansión de su mundo en performances donde traban luchas y negociaciones cosmopolíticas, noción sobre la que me extenderé en el siguiente apartado . $^{5}$.

El documento tiene seis secciones. Luego de la introducción, presento la discusión teórica que sustenta el texto. En el tercer apartado argumento que la circulación de mujeres y hombres negros en la región y su convergencia en el baile/música son formas de crear territorialidad. En las secciones cuarta y quinta profundizo en la acepción de las nociones de juga y fuga: mientras en la cuarta señalo la relevancia de la improvisación y el juego como formas de expresión de la individualidad dentro de la colectividad y como poderosos medios de creación de vínculos sociocosmológicos, en la quinta apunto la reinvención de sentidos que adquiere la palabra y el movimiento de la acepción fugas. Finalmente, en el sexto apartado señalo los encuentros y desencuentros ontológicos que se agencian mediante el baile/música en contextos de escenarios urbanos de amplia concurrencia.

4 Un fragmento de grabaciones de fugas/jugas realizadas en el trabajo de campo puede consultarse en https://youtu.be/34U4CCnRDgY (Palau 2019).

5 Aunque el baile es indisociable de la música, aquí no profundizo en el análisis del sonido musical, para delimitar el tema en discusión. 


\section{Performances en cosmopolítica}

La etnomusicología, la antropología y los estudios de la performance han cuestionado la idea de la universalidad de las nociones occidentales de música y danza señalando su diversidad y difícil aprehensión (Gonçalvez y Osorio 2012). Ambas pueden abarcar diferentes prácticas, como canto, escucha, baile, dramatización; pueden estar articuladas a distintos aspectos de una sociedad, como la política y la religión; y pueden ser conceptualizadas de diferentes modos o incluso no existir en ciertas sociedades. Algunas alternativas conceptuales han buscado ser más abarcadoras, como las nociones de práctica sonora, práctica musical, hacer musical o performance.

De otro lado, la discusión interdisciplinar que reunió en los estudios de la performance a la antropología, el teatro, la lingüística, la etnomusicología, entre otras áreas, ha conceptualizado la performance como el evento donde se negocian, afirman y transgreden las estructuras sociales (Sandroni e Iyanaga 2015; Turner y Bruner 1983). Siguiendo esta línea, la etnomusicología ha resaltado la relevancia de esta noción para comprender el acontecer de las prácticas sonoromusicales como hecho social y performance, donde participan diversos actores en un espacio-tiempo específico (Lucas 2013; Seeger 2015). Así, tanto la fiesta de las Adoraciones al Niño Dios como otros eventos en los que tiene lugar la música/ danza de jugas/fugas pueden ser entendidos como performances. Ahora bien, las fugas/jugas, al igual que otras prácticas locales en un contexto de modernización, adquieren distintos estatutos ontológicos entre baile, música y performance al ir y venir entre fiestas familiares, rituales comunitarios afrocatólicos, festivales y eventos que celebran la afrocolombianidad.

Una primera clave para comprender tal flexibilidad es estudiar el hacer y experimentar musical de la gente, como propuso Titon (2008, 29), con una etnomusicología basada en la fenomenología que señala la relevancia de la experiencia, la sensorialidad y la situacionalidad del saber sonoro. Esta aproximación advierte la centralidad de la articulación de baile y música, la diversidad de actores participantes en un momento específico, y resalta que los sentidos y saberes están anclados en la experiencia y en el evento.

También la idea de sonido pasa por una revisión, que profundizan los sound studies y la etnomusicología, en la que es entendido como la interrelación entre materialidad y metáfora (Feld 2013). Es decir, el sonido es construido por la percepción mediante la vibración y captura por el diseño biológico de nuestros oídos y cuerpos, así como por las asociaciones filosóficas, políticas y culturales que ayuda a configurar (Novak y Sakakeenky 2015). En ese sentido, el sonido es 
puente entre músicas y baile, en la medida en que resuena adentro de los cuerpos y no solo fuera de ellos, incluso con ondas inaudibles en una dimensión sónica, que abarcan el aspecto sonoro restringido a las ondas audibles (Goodman 2010).

Ahora bien, las fugas/jugas se vinculan primero a una trama de sociabilidades de urdimbre histórica, en la que la gente negra del sur del valle del río Cauca comparte con la población afrodiaspórica en las Américas la experiencia de la esclavización de sus antepasados producida por el capitalismo moderno que continúa como colonialidad del poder (Quijano 2000). El catolicismo, instrumento de la colonización y de la esclavización, fue apropiado por la gente negra, que le imprimió formas de sentir y saber mediante las prácticas sonoras y corporales (Maya y Cristancho 2015) que conjugan memorias africanas, resignificaciones y resistencias en suelo americano.

De acuerdo con Ferreira Makl (2011), los estudios sobre las músicas afrolatinoamericanas a lo largo del siglo XX se han realizado desde cuatro enfoques: africanismos, africanías, matrices africanas y africanidades. Este autor señala que los africanismos buscaron retenciones culturales africanas en América, mientras que las africanías indagaron por elementos de culturas africanas específicas. El tercer enfoque, las matrices africanas, se basa en las teorías lingüísticas para el análisis de los sistemas culturales. Finalmente, las africanidades constituyen un proyecto político dirigido a construir una etnicidad. Ferreira Makl utiliza los dos últimos enfoques para sugerir que las prácticas musicales portan códices de resistencia histórica que no se limitan a ella, sino que además constituyen "prácticas vitales portadoras de valores de vida” (59); así mismo, señala que, a través de la música y la danza, los afrodescendientes desarrollaron políticas de la síncopa ${ }^{6}$ que sedujeron a los sectores dominantes, aunque en las prácticas musicales mantuvieron "ambivalencias y tácticas de doble voz" (59). Esta sugerencia resuena con el argumento de Scott (2000), quien afirma que la negociación de los grupos subordinados se expresa cuando estos actúan como si durante las performances aceptaran su situación frente a los grupos dominantes, mientras que en espacios donde los últimos están ausentes cuestionan su legitimidad. Tales argumentos son relevantes para comprender algunas de las negociaciones que se agencian en las fugas/jugas.

En Colombia, la africanidad se consolidó durante la década de los ochenta, cuando el movimiento afrocolombiano apeló a una identidad étnica que logró reconocimiento en la Constitución Política multicultural de 1991, y particularmente con la Ley 70 de 1993, cuya principal reivindicación fue otorgar el derecho a la

$6 \quad$ Una explicación para legos del argot musical sobre la síncopa es: al llevar el ritmo con las palmas, la síncopa constituye los golpes que no coinciden con ellas. 
propiedad colectiva de la tierra para las comunidades de la costa pacífica (Pardo 2016). Con este proceso, las músicas afrocolombianas se tornaron índices étnicos que contribuyen a la performatización de las etnicidades afrocolombianas en diferentes escenarios, algunos de los cuales constituyen una arena de disputa donde la población afrocolombiana rural y urbana negocia mayor visibilidad y una identidad étnico-racial frente a los sectores dominantes que impulsan la lógica de la espectacularización. Carvalho (2002) ha apuntado que la expansión de músicas afrolatinoamericanas a circuitos más amplios actúa en vía doble, pues al tiempo que permite mayor visibilidad y acceso a recursos de poblaciones locales, ocurre una negociación en la que las músicas se adaptan a las exigencias del mercado e, incluso, algunas de ellas reducen sus sentidos o se muestran como formas de entretenimiento. Esto responde a longevos estereotipos de sensualización del oído-mirada occidental (Bohlman y Radano 2000; Carvalho 2002).

Por otra parte, a diferencia de las perspectivas que exaltan solo la dimensión simbólica y epistemológica de los saberes musicales y las prácticas sonoras, entiendo el baile y la música fugas/jugas como acustemologías, noción propuesta por Feld $(2013,2017)$ al unir la acústica y una acepción de epistemología basada en la experiencia colectiva localizada. De acuerdo con este autor, las acustemologías son formas de saber y de estar en el mundo a través del sonido, de manera que las fronteras entre epistemología y ontología se funden en la experiencia sónica subjetiva y en la práctica compartida. Otros estudiosos de la antropología y la etnomusicología han señalado la inseparabilidad de los procesos epistemológicos y ontológicos construidos por la experiencia sónica en colectivos indígenas en Brasil (Stein 2015) y Colombia (Martínez 2017).

La acustemología local de la gente negra es heterogénea y está atravesada por tensiones de diverso tipo. La experiencia histórica de algunas redes campesinas de gente negra en el sur del valle geográfico del río Cauca llevó a la configuración de una ontología relacional que entiende el territorio como la vida misma, con lo cual se aleja de la separación moderna entre naturaleza y cultura (Mina et al. 2015). Desde la segunda mitad del siglo XX, a partir de la perspectiva capitalista moderna, la región se transformó en un "lugar producido por el desarrollo” (Rojas 2016, 215), proceso que la gente negra experimentó en negociación y en pugna con tales intervenciones, en encuentros y desencuentros ontológicos.

De la Cadena (2010) observa que las disputas en la esfera política que adelantan los movimientos indígenas exceden la visión tradicional de lo político para llamar la atención sobre la participación de entidades no humanas que, desde la perspectiva moderna, habían sido relegadas a manifestaciones culturales o del folclor. Basada en la noción de cosmopolítica, esta autora señala que en la disputa pública participan entidades inimaginables para la perspectiva de la política 
occidental. Para comprender su argumento, debemos remitirnos a la propuesta de cosmopolítica de Stengers (2014), que sugiere considerar lo múltiple y lo divergente de los mundos en la cuestión política, en situaciones concretas en las que "todos tienen que estar presentes de manera de darle a la decisión su máximum de dificultad” (17). En el mismo sentido, las músicas-bailes afrocolombianas de la región han sido concebidas desde una perspectiva occidental como expresiones culturales, segregándolas así de su expresividad política. Específicamente, se puede entender que la puesta en presencia de todos, alegada por la propuesta cosmopolítica (Stengers 2014), se da en el momento de la performance en fiestas, festivales y otros eventos de jugas/fugas, donde se disputan la continuidad de la vida de la población negra y la vida del territorio, entendidos de modo indisociable como una ontología particular. Esta disputa y esta negociación ocurren mediante la invitación constante que las personas expertas en los saberes musicales/dancísticos hacen a vecinos, aliados y actores “externos” — que no comparten las mismas premisas sobre la vida colectiva y el territorio- a participar de las prácticas sonoras y crear así redes intercomunitarias en expansión.

Si bien para Stengers (2014) la cosmopolítica implica la construcción de un mundo común, Blaser (2016) apunta —en su estudio sobre el debate entre colectivos indígenas y otros actores en Canadá en torno a una "entidad natural”- que también es plausible una cosmopolítica que no implique la creación de mundos u ontologías comunes y que posibilite el cuidado de la vida para todos los involucrados. Considero que el argumento de Blaser nos permite comprender lo que ocurre en la performance de las jugas/fugas con la participación de múltiples actores y acustemologías diferentes que, no obstante, han impulsado su revitalización.

De acuerdo con Carozzi (2009), los saberes del baile en el tango, como en otros, presentan una dimensión esotérica o un secreto. A simple percepción y de acuerdo con las narrativas de "facilidad” e "inclusión” en el baile/música de las fugas/jugas por parte de mis interlocutores, se pensaría que no hay en ellas ocultación alguna. Sin embargo, el secreto de los saberes de las fugas/jugas consiste en que la narrativa del saber fácil y accesible a todos no necesariamente crea mundos comunes, aunque sea una estrategia para el fortalecimiento de sus epistemologías-ontologías sónicas.

Pensando el baile/música a través del anterior marco conceptual y de mi experiencia en campo, quiero sugerir una interpretación que exploraré en este texto. Las fugas/jugas se basan en acustemologías que - a pesar de confrontarse con escenarios de espectacularización y aun en los propios territorios que habita la gente negra, donde se configuran ontologías relacionales y territorialidades heterogéneas - participan y agencian disputas cosmopolíticas en performance. En particular, sostengo que los múltiples significados y movimientos de las 
fugas/jugas articulan políticas-saberes-afectos basados en una epistemologíaontología sónica que, al ser puesta en escena, invita a la participación de actores más allá de fronteras humanas y étnico-raciales como una estrategia vital de la gente negra. Al mismo tiempo, en esta práctica subyace el riesgo permanente de la transformación de los significados y de la reproducción de las condiciones de dominación. Denomino a esta pulsión integradora alianzas sónicas. En las siguientes líneas exploro esta interpretación.

\section{Adoraciones al Niño Dios: la invitación a un encuentro de caminos}

El baile-música de las fugas o jugas tiene su principal ocasión en la fiesta de Adoración al Niño Dios, una expresión de apropiación del catolicismo celebrada en distintos poblados entre diciembre y marzo. Dado el protagonismo de ese bailemúsica en la Adoración, también a la fiesta se le llama así. De acuerdo con un hombre organizador del evento, la “Adoración es como demostrar el amor”, a lo que una mujer negra mayor o mayora, también organizadora, añade: "Se arrulla al Niño, con loas, coplas y jugas”, lo que abarca varias prácticas musicales y performáticas.

Durante la Colonia, esta región geográfica estuvo ocupada por haciendas esclavistas y vastas zonas de bosque seco. Con la evangelización católica realizada en las haciendas mediante los autos sacramentales, nacieron las dramatizaciones y los cantos que, posteriormente, cobraron independencia de la Iglesia con la autoridad de las mujeres negras y dieron origen a las Adoraciones al Niño Dios (Atencio Babilonia y Castellanos 1982) y a otras prácticas musicales que constituyeron espacios de fortalecimiento del vínculo social (Sevilla 2009), basados en sus creatividades y resistencia (Velasco Díaz 2016). Muñoz (2016) señala que, en la época de la esclavitud, los afrodescendientes "tomaban prestada” o "robaban" temporalmente la imagen del Niño Dios para hacer su celebración después de atender a las familias terratenientes en las haciendas y de que estos retornaran a Popayán.

De acuerdo con las voces de mayoras y mayores, en las décadas pasadas se transformó la "naturaleza”, así como las prácticas musicales de la fiesta. Así, en la vereda Santa Rosa del municipio de Caloto, ya no se le canta a un tipo de pájaros, las guacharacas, pues, como afirma una cantora, "para qué si ya no hay”. Mientras que "antes toda la noche era solo jugas”, en la actualidad las Adoraciones han 
incluido la reproducción de músicas populares comerciales. Las filas de juga se deshacen intercaladas con los bailes de pareja — sin perder sacralidad - y abarcan, de modo simultáneo, otro tipo de sociabilidades. Esta transformación se dio en toda la región.

Con la amplificación sonora y el crecimiento de las fiestas, el volumen aumentó hasta hacerse indispensable, animando el baile y añadiendo vibraciones sónicas inaudibles (Goodman 2010) que atraviesan cuerpos y territorios. Es decir, los cambios en las prácticas musicales se dieron de modo simultáneo a la construcción de la territorialidad heterogénea que, para algunos, se basaba en la ontología relacional del territorio como la vida, aunque en conexión con diferentes ontologías y permeada por las distintas transformaciones socioeconómicas que tuvieron lugar en el siglo XX (Mina et al. 2015).

Así, la urbanización, la modernización y la consecuente adopción de una economía capitalista desplazaron en algunos lugares a las economías basadas en la solidaridad y la reciprocidad, como las fiestas rurales de fugas/jugas y otras prácticas musicales que fueron vistas como “atrasadas”. En otros casos, la expansión extractivista de la agroindustria de la caña de azúcar —que tuvo lugar en el norte de la región desde la segunda mitad del siglo XX- obligó a la proletarización y a la conurbación del campesinado, procesos que conllevaron un empobrecimiento. Con estos, también ocurrió una reconfiguración socioeconómica y acustemológica (Feld 2013) de las Adoraciones.

Es certera la observación de Atencio Babilonia y Castellanos (1982) realizada hace cuatro décadas, cuando afirmaron que las Adoraciones creaban una comunidad transitoria que no necesariamente abarca la población entera de una comunidad, sino que se renueva en forma de red intercomunitaria, a la cual se convocan diferentes actores para construir alianzas sónicas mediante las prácticas musicales y las corporalidades en performance que construyen territorio con su movimiento. Así, según algunos interlocutores, hay personas de allí a las que no les gustan las jugas, y hay antiguos pobladores y vecinos que, viviendo en otros lugares, van a las jugas y circulan entre las fiestas regionales.

A pesar de que la mayoría de los asistentes son gente negra de la comunidad, acuden también algunas personas de veredas vecinas y que han emigrado a las ciudades, indígenas, blanco-mestizos y extranjeros curiosos. "Aquí invitamos a todo el mundo, pero esta es una fiesta de negros”, me aclaró una mujer dueña de la fiesta. Ahora bien, se trata de una red que traza el territorio en su vínculo con la circulación de personas.

Algunas asistentes de la comunidad y de veredas vecinas son mujeres a quienes les gusta “adorar al Niño” y van en moto, en bus o caminan kilómetros de una vereda a otra para participar en las jugas, en las que bailan incansablemente 
durante largas horas. Con gran fortaleza bailan toda la noche en suelos de tierra, por lo cual, a veces con humor, les llaman patirrucias, es decir, "patas rucias". Su circulación teje la red que establece la territorialidad común a mucha gente negra de la región, aunque no a toda, dada la heterogeneidad de su experiencia. Con la concurrencia a las jugas y con las patirrucias, aprendí que este baile implicaba el encuentro de caminos iniciado mucho antes, desde el lugar de vivienda como mapa de la territorialidad, aunque esta no fuera compartida por todos los asistentes y convocara a todos aquellos que, además de la gente negra, quisieran participar “adorando”. Es decir, el suelo sobre el que se baila no es el mismo para todos: es lugar de encuentro para migrantes, territorialidad vital para moradores, palco de diversión para el público en eventos en las ciudades, suelo extranjero para visitantes y parada en el camino para los vecinos y las mayoras bailadoras.

\section{Las jugas como juego: improvisación y participación}

Siempre he visto que el baile de jugas inicia un instante después de las primeras notas melódicas de la trompeta o el violín con la primera persona en salir a la que siguen todos los participantes formando una fila de baile. Viejos, jóvenes y niños integran filas que crecen tomando rumbos circulares o sinuosos, de acuerdo con los pasos del líder de la fila, entrecruzándose, rompiéndose y rearmándose en nuevas filas. Jugas de letras religiosas o que remiten a asuntos del trabajo campesino y otras que tratan distintos asuntos con humor suenan en cualquier evento, fiesta y festival.

Al inicio, hace más de una década, yo, una blanca-mestiza y extranjera —en el sentido de extraña- de la vecina ciudad de Cali, recién llegada a los territorios negros del sur del valle del río Cauca, tenía el imaginario estereotipado difundido por Occidente sobre el virtuosismo dancístico de los cuerpos negros (Bohlman y Radano 2000), por lo que observaba con respeto y timidez. Tampoco tales prácticas musicales se limitaban a la percusión, pues las alimentaban las cuerdas y los vientos (Palau 2010). Otras prácticas musicales negras también se alejan de tales estereotipos, como señalan Larraín y Madrid (2018), cuando refieren la instrumentación de cuerdas usada por una población negra en Antioquia, otro valle interandino colombiano con una historia similar. Vi que estaba equivocada cuando percibí que los distintos movimientos en las jugas no buscaban precisamente grandes agilidades y un solo paso básico bastaba. Debí deconstruir 
esta idea respecto a tales corporalidades para observar y practicar junto a los danzantes. Además, las mayoras, quienes más contienen sus movimientos, son consideradas las expertas en el dominio de este saber. No obstante, no se trata de un saber exclusivo. Eran ellas quienes me invitaban a unirme al baile ondeando sus faldas o con la pregunta “¿Ya bailó juga?”. Así, las jugas suman la voluntad individual de bailar y la coordinación colectiva al seguir a otros y ser seguido con el mismo ritmo en los pies.

Durante las Adoraciones o jugas, hay momentos específicos en los que niños y adultos se visten como los personajes de la Natividad, bailan "con mucho respeto" - de acuerdo con las mayoras-y dicen versos frente a los espectadores que interrumpen el baile en ese momento. Los Reyes Magos, los pastorcitos, María y José, entre otras figuras, bailan en círculos con deferencia y devoción “adorando al Niño Dios” representado en una imagen que reposa en un pesebre. También la mula y el buey tienen su propio baile de jugas con un carácter más alegre, aunque se muestran un poco torpes dando pequeños empujones hacia el público. Frente al Niño Dios, los bailarines hacen una vuelta sobre su propio eje que también aparece en cualquier curva del baile cuando ingresa el resto de los asistentes.

A veces se forman varias filas distinguidas por generación. Presencié las filas donde bailan los mayores, principalmente mujeres a un ritmo más pausado, con un paso fijo, un moderado ondear de sus faldas y movimientos contenidos. En otras ocasiones, los jóvenes varían los gestos de acuerdo con lo que plantee el primero de la fila, creando pasos novedosos y divertidos. Mientras que la improvisación en el baile es relevante entre jóvenes y adultos, los adultos mayores apuntan que es una novedad introducida en décadas recientes y que descuida la reverencia de adorar que deberían expresar.

Algunos indican que se dice juga, enfatizando la fonética de la jota, porque se trata de un juego, de la diversión colectiva mediante la experiencia del goce y la creatividad. En otra ocasión, una mujer me señaló que "se dice juga porque al Niño Dios le gusta jugar”, lo que sugería una concepción humanizada de la figura católica, consonante con algunas letras de jugas y tal como se manifiestan otros catolicismos negros del país (Arocha et al. 2008).

En el municipio de Suárez, sobre la cordillera Occidental, la ruptura generacional es más fuerte y pauta los espacios de jóvenes y de mayores, tanto en el hacer musical como en el baile (Lora 2017). Un anciano de la vereda de Dominguillo (municipio de Santander de Quilichao) me explicó que antes al bailemúsica le llamaban arrullos o adoraciones y se restringía a letras religiosas: "Se bailaba con mucho respeto y no se bebía licor. Hoy en día los jóvenes hacen muchas payasadas; por eso les dicen jugas, ya no son solo arrullos o adoraciones. Ha cambiado mucho la tradición”. En efecto, en muchas ocasiones observé las filas 
que improvisaban los pasos: extendían los brazos haciendo el movimiento de “avioncito”, bajaban y subían ondeando, la mano tras la oreja y la otra sobre la cadera, arrastrando una pierna tiesa... "Lo que les gusta es la recocha”, dijo una vez una mujer entre risas y crítica.

Yo llevaba varios años disfrutando del paso “ortodoxo” de la juga, pero como extranjera vecina y debido a mi timidez y falta de confianza con los demás, no me había atrevido a participar de las improvisaciones. Fue junto al grupo musical Aires de Dominguillo — conformado por algunos integrantes de la familia Lasso Caracas, con quienes establecí una relación cercana en campo- como comencé a intervenir en el baile. A ellos se sumó mi voluntad y una nueva invitación: “¡Vamos!”. Solo después de esta experiencia, fue más evidente para mí que el baile de jugas se practica junto a conocidos, vecinos y familiares en un ambiente de confianza y con los que se juega a plenitud. Luego, uno de ellos, joven, me dijo: “Antes yo me la pasaba jugando con mis amigos”. Es decir, lo que yo desde el inicio había caracterizado como baile era señalado como juego.

Las jugas coinciden con lo que Quintero (2009) llama músicas mulatas y que resignifica el origen peyorativo del término: expresiones de matriz africana que emergieron de hibridismos a lo largo de procesos históricos semejantes en América, que no disocian el baile de la música, lo vocal de lo corporal; donde el colectivo manda y los solistas adornan sobre la estructura, y no tienen un único principio centralizador. Sin embargo, aunque comparten características con las músicas afrolatinoamericanas, como los cantos responsoriales, cierta circularidad y ritmos en síncopa (Ferreira Makl 2011; Quintero 2009), tales estructuras sonoras no se restringen a las musicalidades negras locales, pues también son comunes a los diversos mundos sonoros e identidades sociales vecinos. Así, Miñana (1997) apunta que el bambuco engloba a una gran cantidad de músicas del suroccidente y centro de Colombia que atraviesan todas las camadas étnicoraciales desde hace más de dos siglos.

En ese sentido, como percibí en mi experiencia, la improvisación, ampliamente extendida en las músicas de matriz negra, es más común en el baile que en el sonido de las jugas y se trata de una manifestación de la individualidad dentro del colectivo. Durante su recorrido por un territorio en forma de baile y dando continuidad a los caminos intercomunitarios, el cuerpo se convierte en el lugar privilegiado para la creación individual con base en el paso básico. Es mediante la improvisación y el juego como se crean alianzas sónicas que afirman el vínculo social, que invitan a la participación no solo de la gente negra de todo el territorio, sino de los seres que pueblan el mundo: indígenas, mestizos, extranjeros, los Reyes Magos, el Niño Dios y todos sus parientes. 


\section{Las fugas como huida: aprendizaje y ancestralidad como porvenir}

En otro sentido y en sintonía con la construcción de una identidad étnico-racial, las fugas/jugas pueden ser descritas como una estrategia de huida de los antiguos esclavizados, apelando a la variación de fuga, con efe (f). Como me explicó un músico, las "fugas se hacían cuando les daban permiso a los esclavos; era cuando ellos aprovechaban para fugarse; por eso se baila en fila, para que fuera más fácil escaparse uno por uno”. Más allá de la imposibilidad de comprobar la veracidad histórica del hecho, me interesa resaltar que es la narrativa compartida la que se torna relevante, en cuanto tiene efectos de verdad al señalar la capacidad de agencia de sus antepasados.

La población afrocolombiana ha gestado procesos políticos de identificación étnica con la creación de consejos comunitarios y organizaciones, y ha insertado sus disputas en el campo jurídico con proyectos de búsqueda de autonomía territorial en el escenario multicultural abierto por la Constitución Política de 1991 y la Ley 70 de 1993 (Pardo 2016; Vanegas Muñoz y Rojas 2012). En este proceso, las músicas afrocolombianas se convirtieron en índice de una identidad étnico-racial. No es extraño entonces que muchos músicos, bailarines, gestores culturales y organizadores de fiestas religiosas sean también líderes comunitarios y sociales, promotores de la identidad étnico-racial. Lo anterior se da en el marco de un multiculturalismo neoliberal (Hale 2014), según el cual el neoliberalismo no se restringe a lo económico, sino que constituye un proyecto de gobernanza que otorga "reconocimiento cultural" sin una "redistribución material” (23). Paradójicamente, este reconocimiento ha hecho que la concesión de derechos de propiedad territoriales afroindígenas en América Latina sea compatible con el neoliberalismo. Parte de la dificultad de la lucha por una autonomía territorial para los afrocolombianos en la región, además de no poseer extensos territorios titulados como en la costa pacífica ${ }^{7}$, es la superposición de múltiples territorialidades en conflicto o en alianza con colectivos indígenas, conglomerados empresariales y actores armados ilegales.

\footnotetext{
La población del sur del valle del río Cauca no fue abarcada en el logro de la titulación de un poco más de 5 millones de hectáreas para las comunidades negras de la costa pacífica, debido a que, supuestamente, la mayor parte de la región está a nombre de particulares, a diferencia de la costa cuyos territorios eran baldíos y de la dispersión urbana de la población afro. Sin embargo, la Asociación de Consejos Comunitarios del Norte del Cauca (Aconc) actualmente agrupa más de cuarenta consejos que exigen la titulación colectiva, entre otras demandas.
} 
Una herramienta del movimiento afrocolombiano vinculada con la disputa territorial es la noción de ancestralidad, inicialmente guiada por la idea de etnicidad indígena. Se trata de una idea que remite al pasado como proyecto del futuro o lo que Valencia García (2018) entiende como porvenir de los recuerdos, un modo de construir memorias en el que los grupos subalternizados imaginan lo que se quiere recordar en un intento de incidir en el futuro. Así, conectando pasado, presente y futuro y resaltando las destrezas de la gente negra, una cantora y organizadora de las Adoraciones al Niño Dios afirma que "la fuga es la inteligencia de nuestros ancestros", que carga una "nostalgia africana”, y manifiesta su deseo por “dejar la tradición a [los] nietos”. La ancestralidad conjuga entonces una africanidad, entendida como un proyecto de construcción de una identidad (Ferreira Makl 2011), al tiempo que una ontología relacional en la que, recordemos, el territorio es entendido como un entramado con la vida humana y otros actores. Pero también se vincula a la experiencia sónica y cimenta la memoria fragmentada, las sensorialidades y las corporalidades amarradas a ella. De modo que la narrativa de la ancestralidad en la versión de las fugas como huida, que resalta la agencia de los sujetos esclavizados para luchar contra sus constreñimientos, es movilizada en el baile y construye una historia de reverberaciones futuras. También habla de una capacidad de los antepasados que vive en la gente negra, que tiene el desafío de huir de las formas de dominación contemporáneas. En tal sentido, en el baile de fugas se materializan y se entraman el olvido y el aprendizaje, la reinvención y la resistencia.

El siguiente es uno de los momentos en campo en que percibí este entrelazamiento. El 24 de diciembre de 2017 viajé, junto al grupo Aires de Dominguillo, desde el campo de Santander de Quilichao hasta una vereda en las altas y frías montañas occidentales, a la celebración del Nacimiento. Había sido un largo viaje en ascenso a la cordillera Occidental por una carretera destapada en una pequeña camioneta donde nos apretábamos junto a los instrumentos musicales y los equipos de sonido. Aires de Dominguillo había ido en varias ocasiones durante los diez años anteriores con el compromiso de tocar en la fiesta hasta el amanecer.

Ahí las filas de baile no se formaban tan rápido como en otros lugares; algunos jóvenes bailaban con timidez, mientras que otros se reían de ellos, ¿jugando? Una mujer mayor entraba intermitentemente al espacio destinado a las fugas y, con experto movimiento de bailadora y seguro también de caminante, arrastraba tras de sí a algunas personas. Entré a la fila de baile con mi paso 
convencional y un señor muy animado y un poco borracho se unió a la fila y comenzó a gritarles a todos mientras bailaba: “¡Entren! ¡Bailen, que luego no van a quererse salir!”. Me dijo: “Me gusta que esté aquí porque esto es de negros”. Así, revelaba las tensiones raciales respecto a mi tez clara y, al mismo tiempo, extendía la invitación a participar, como ya había experimentado antes. En el momento del Nacimiento, a las doce de la noche, la mayoría de los participantes jóvenes dudaban de qué hacer hasta que una joven exclamó: “¡Ella sabe qué sigue ahora!”, refiriéndose a doña Ana, la cantora del grupo y organizadora de su propia fiesta de Adoraciones. Doña Ana les indicó los versos, cantos y bailes que debían hacerse en ese momento. Los jóvenes se apresuraban a anunciar que serían los padrinos del Niño Dios, o sea, quienes se encargarían de coordinar y reunir los recursos para financiar la fiesta el siguiente año. Fue un proceso de aprendizaje entre la reinvención y la restauración del olvido de tales prácticas sonoras.

A la mañana siguiente, una de las señoras organizadoras nos comentaba: "Hacemos esto por nuestra cultura y porque lo hacían nuestros ancestros; estamos tratando de recuperar la memoria de lo que hacían ellos. Ahora que estamos con lo del consejo comunitario, para nosotros esto es importante”. Eran los tiempos de negociación del proceso de paz entre el Gobierno y la guerrilla; el verde brillante de las plantaciones de coca que cubrían las montañas y la minería aurífera ilegal y de empresas representaban extractivismos que significaban poner en riesgo la vida. Mientras tanto, la comunidad experimentaba una tensa calma con la esperanza de un futuro tranquilo en el territorio; una esperanza que era bailada, cantada, tocada y tejida en alianzas sónicas de redes intercomunitarias, en el proceso de aprendizaje de una memoria colectiva fragmentada, no obstante impulsado por su concepción de ancestralidad para moldear el futuro.

En los últimos tres años se ha hecho más visible el asesinato de líderes sociales en el país. Irónicamente, este fenómeno ha alcanzado su pico a partir de la firma del acuerdo de paz entre el Gobierno nacional y las Fuerzas Armadas Revolucionarias de Colombia (FARC-EP) en 2016. En este contexto, los recientes procesos de aprendizaje y reinvención de las fugas constituían, además de la afirmación de una memoria que resaltaba la agencia de ancestros esclavizados con sus fugas, formas contemporáneas de huir en sí mismas, mediante el baile/ música, para pervivir en medio de las violencias avivadas por los extractivismos y el conflicto armado. Y, simultáneamente, constituían maneras de retornar al territorio, entendido como la vida presente y futura, y de construirlo en cada paso bailado. 


\section{Un baile con democracia: paradojas de la difusión}

Al norte de la región, en Cali, la gran capital del suroccidente colombiano, una amplia población es afrocolombiana; parte de ella tiene su morada en el norte del Cauca, desde donde se desplaza para trabajar en la ciudad en un proceso de conurbación. En tal contexto, otro aprendizaje y otra transformación del bailemúsica han sucedido y nuevas tensiones se han puesto en juego: las fugas ingresaron al Festival de Músicas del Pacífico Petronio Álvarez en el 2008 - un evento centrado en músicas afrocolombianas, aunque su nombre no lo explicite-cuando se creó la categoría de violines caucanos, en los grupos de cuerdas, percusión y voces. El Petronio — como se le dice de modo coloquial—, que emerge en pleno auge de la nueva Constitución multicultural de 1991, es una arena de disputa que ha logrado la visibilidad de la diferencia cultural afrocolombiana e interpela a la amplia población negra de la ciudad y alrededores, al tiempo que opaca las condiciones de desigualdad socioeconómica de la población afro con la espectacularización del evento.

Dicho evento reúne varias expresiones musicales afrocolombianas, como los conjuntos de marimba, declarados Patrimonio Cultural Inmaterial de la $\mathrm{Hu}-$ manidad por la Unesco en 2010 con el nombre de "Música de marimba y cantos y bailes tradicionales de la región colombiana del Pacífico sur y de la provincia ecuatoriana de Esmeraldas”. Al igual que sucedió con los más conocidos conjuntos de marimba, las fugas ${ }^{8}$ iniciaron un proceso de transformación con arreglos más complejos y virtuosos y corporalidades moldeadas para la puesta en escena, en una separación clara entre público e intérpretes (Ó. Hernández 2010). Además, se articularon a procesos de larga escala que han llevado a las músicas tradicionales afroamericanas a la espectacularización, y en este proceso las formas performáticas de juego, drama y ritual se orientan a la creación de géneros musicales populares (Carvalho 2002).

Entre 2008 y 2009, cuando asistí a las primeras versiones del festival en las que participaron los grupos de violines caucanos, observé que no se formaban las filas de baile de fugas por desconocimiento del público, mientras que se había popularizado una serie de pasos estandarizados por folcloristas en procesos de aprendizaje informal en el festival desde años anteriores. En 2017 dos interlocutores jóvenes iniciaron de modo espontáneo la coordinación del baile al que

8 También las fugas/jugas y la nueva categoría de los violines caucanos son objeto de procesos de patrimonialización que no examino en este texto. 
las personas circundantes nos unimos en un híbrido de fila de jugas y ondear de pañuelo, con los pasos del currulao, la práctica musical más conocida de la música de marimba de la costa pacífica. El alto volumen animaba los cuerpos más allá de lo audible, en lo que Goodman (2010) ha apuntado como su espectro sónico en contraste con lo que se ha entendido como sonoro. Había un carácter de alegría, de juego y, por supuesto, no de arrullo religioso; no obstante, la improvisación estuvo controlada dentro de las variaciones de los pasos folclóricos establecidos y los más excéntricos, como “el avioncito” o "la pierna tiesa”, no aparecieron, pues tienen convenciones para que puedan ocurrir: unos proponentes y unos seguidores unidos por el conocimiento mutuo, de modo que la confianza impulse el juego y la improvisación, con una base de solidaridad social.

Para el Petronio, Jose Edier, cantor y director del grupo Puma Blanca, del municipio de Buenos Aires, compuso Así se baila la juga, canción que invita al amplio y heterogéneo público del festival a participar en la juga, anunciando que se trata de "un baile con democracia":

Un baile con democracia,

Se baila la juga (coro)

Sea hombre o sea mujer

Se baila la juga

Aquí no hay discriminación

Se baila la juga

Sea niño, joven, viejo

Se baila la juga

Solo métase al montón

Se baila la juga

Se baila en forma de trencito

Se baila la juga

$\mathrm{Y}$ no te pueden coger

Se baila la juga

Y lo que hace el de adelante

Se baila la juga

Así mismo vas a hacer

Se baila la juga

Así, así,

Se baila la juga

Así como antes describí la invitación a participar como una forma de ampliar el mundo y el territorio en las Adoraciones al Niño Dios, nuevamente este 
impulso de convocar aliados mediante el baile aparecía en escena en un festival de asistencia masiva. También don Walter, violinista en Aires de Dominguillo y líder comunitario, afirma con satisfacción que "las fugas ya las baila todo el mundo, el indio, el mestizo... ya no son solo de negros”. Se reitera que es un baile “de todos”, de gran facilidad e inclusión: “Doña Ana, ¿me enseña a bailar juga?”, y ella respondía entre risas, con sarcasmo: “Para lo difícil que es bailarla!”.

Estas narrativas apuntan a la creación de alianzas sónicas con actores externos; buscan afectarlos mediante los saberes incorporados, lo que va más allá de un sentido de goce efímero o de la afirmación de una identidad étnico-racial. Se trata de que el afecto del movimiento bailado y cantado lo trascienda para instaurar su potencia en una política vital, en una ontología donde la política excede la perspectiva moderna (De la Cadena 2010) y atraviesa las prácticas musicales que en el escenario del festival han sido concebidas como "músicas tradicionales” o folclor. Así, las fugas/jugas cargan una potencia bailada que se presenta como fácil, accesible a todos, como un baile democrático que, sin embargo, aun pasando por una espectacularización y por reglamentos musicales, no ve reducidos sus múltiples significados al de una música para el goce.

La retórica de la simpleza y de la democracia es constituida por múltiples capas donde la afectación del baile como juego, como narrativa de fuga y ancestralidad en la agencia de un porvenir de los recuerdos (Valencia García 2018), en el impulso individual de componer la fila de baile, se entrama con discursos ocultos (Scott 2000) de una memoria en resistencia de un grupo históricamente subordinado. "Es una forma de mantenernos unidos y hacer resistencia pacífica”, respondía José Edier a una periodista. Y aun cuando las fugas/jugas se manifiestan como poderosas prácticas de afectación y creación de vínculos con la narrativa y los movimientos de un saber "fácil”, "para todos”, un dominio experto, entramado en su acustemología, está latente en sus giros.

Carozzi (2009) llama secreto a la dimensión esotérica que atraviesa las relaciones de saber-poder y que en el baile del tango consiste en la "ignorancia deliberada” con la cual la mujer debe ceder el control de sus movimientos a la guía del hombre. En ese sentido, el secreto de la narrativa del saber común consiste en que las alianzas sónicas son posibles para fortalecer una política colectiva de la vida durante performances cosmopolíticas, aun cuando no siempre construyan ontologías comunes, como sugiere Blaser (2016) con otra interpretación de la cosmopolítica. Se trata de alianzas sónicas no necesariamente verbalizadas, es decir, prácticas fundamentalmente participativas mediante el baile y el canto.

Finalmente, otro caso de expansión de los saberes jugueros hacia actores más allá de su mundo advierte que la negociación con un multiculturalismo neoliberal (Hale 2014) aún rendirá muchas reconfiguraciones y estrategias en las 
que distintas ontologías se disputarán o convergerán en una cosmopolítica. Tal como la vecina ciudad de Cali creó hace unos años el Salsódromo por su amplia tradición salsera, inspirada en el Sambódromo brasilero, el Fugódromo de la Cámara de Comercio del Cauca, realizado en Santander de Quilichao en diciembre de 2019, pretendió ser un “centro comercial a cielo abierto” (S. Hernández 2019). Acompañados de violines caucanos, varios grupos de danzas formales creados en las veredas recorrieron algunas calles bailando jugas, mientras el público observaba inmóvil. Alrededor había una exposición de artesanías, moda y gastronomía. A pesar de la intención de movilizar la economía, de acuerdo con un bailarín, ninguno de ellos recibió un pago por su participación, de modo que fue la práctica menos beneficiada económicamente. Sin embargo, los conjuntos de danzas, muchos de ellos en realidad grupos de adultos mayores, acogieron el evento con entusiasmo. Mientras exhibían imágenes del Niño Dios y pabellones de colores, como en las Adoraciones, afirmaron que venían "para darnos a conocer y mostrar el legado de nuestros ancestros”. En ese sentido, más allá de la perspectiva mercantilista que promovía el evento, los bailarines lo consideraron como la posibilidad de seguir afirmando redes de baile-música-fiestas y establecer alianzas sónicas en la ciudad con nuevos actores.

Así, en ambos casos reaparece la tentativa de crear alianzas sónicas por parte de los saberes-políticas-afectos jugueros o la acustemología de las fugas/ jugas que se moviliza en los nuevos escenarios urbanos, insertados en lógicas del multiculturalismo neoliberal que tienden a reducir los sentidos en juego. Esto no desalienta a los actores, quienes aceptan los desafíos que se abren ante ellos, incluso a costa de los riesgos que esto pueda conllevar.

\section{Referencias}

Arocha, Jaime, Sofía González, Lina del Mar Moreno, Dilia Robinson, Juliana Botero, Alfonso Cassiani, Alejandro Camargo, Carlos Andrés Meza, Oscar Almario, Mario Diego Romero, Zamira Díaz, Cristina Lleras y Ramiro Delgado. 2008. Velorios y santos vivos: comunidades negras, afrocolombianas, raizales y palenqueras. Bogotá: Museo Nacional de Colombia.

Atencio Babilonia, Jaime e Isabel Castellanos. 1982. Fiestas de negros en el norte del Cauca: las Adoraciones del Niño Dios. Cali: Universidad del Valle.

Blaser, Mario. 2016. "Is another cosmopolitics possible?”. Cultural Anthropology 31 (4): 545-570. https://doi.org/10.14506/ca31.4.05 
Bohlman, Philip V. 1992. "Ethnomusicology's challenge to the canon; the canon's challenge to ethnomusicology”. En Disciplining music, editado por Katherine Bergeron y Philip Bohlman, 116-136. Chicago: The University of Chicago.

Bohlman, Philip y Ronald Radano. 2000. "Music and race, their past, their presence”. En $\mathrm{Mu}$ sic and the racial imagination, editado por Philip Bohlman y Ronald Radano, 1-45. Chicago: The University of Chicago.

Carozzi, María Julia. 2009. "Una ignorancia sagrada: aprendiendo a no saber bailar tango en Buenos Aires”. Religião e Sociedade 29 (1): 126-145. https://doi.org/10.1590/S010085872009000100006

Carvalho, José Jorge. 2002. "Las culturas afroamericanas en Iberoamérica: lo negociable y lo innegociable”. En Iberoamérica: diagnóstico y propuestas para el desarrollo cultural, editado por Néstor García Canclini, 97-132. Madrid; Ciudad de México: OEI/Santillana.

De la Cadena, Marisol. 2010. "Indigenous cosmopolitics in the Andes: conceptual reflections beyond 'politics””. Cultural Anthropology 25 (2): 334-370. https://doi.org/10.1111/j.15481360.2010.01061.x

Feld, Steven. 2013. "Una acustemología de la selva tropical”. Revista Colombiana de Antropología 49 (1): 217-239. https://doi.org/10.22380/2539472X79

—. 2017. "On post-ethnomusicology alternatives: acoustemology”. En Ethnomusicology or transcultural musicology?, editado por Francesco Giannattasio y Giovanni Guiriati, 82-98. Údine: Nota.

Ferreira Makl, Luis. 2011. "Artes musicais na diáspora africana. Improvisação, chamada-e resposta e tempo espiralar”. Outra Travessa 11: 55-70. https://doi.org/10.5007/21768552.2011n11p55

Gonçalves, Renata de Sá y Patrícia Osorio. 2012. "Apresentação: dossiê Antropologia da Dança”. Antropolítica 33: 13-23. https://doi.org/10.22409/antropolitica2012.0i33.a41484

Goodman, Steve. 2010. Sonic warfare: sound, affect, and the ecology of fear. Cambridge: The MIT Press.

Hale, Charles. 2014. "Entre lo decolonial y la formación racial: luchas afro-indígenas por el territorio y por (¿o en contra de?) un nuevo lenguaje contencioso". Cuadernos de Antropología Social 40: 9-37. http://revistascientificas.filo.uba.ar/index.php/CAS/article/view/1276

Hernández, Óscar. 2010. "De currulaos modernos y ollas podridas”. En Músicas y prácticas sonoras en el Pacífico afrocolombiano, editado por Carolina Santamaría, Juan Sebastián Ochoa y Manuel Sevilla, 237-284. Bogotá: Editorial Universidad Javeriana.

Hernández, Sophia. 2019. "Histórico, así se vivió el Fugódromo en Santander de Quilichao”. Proclama del Cauca, 9 de diciembre. https://www.proclamadelcauca.com/historico-asi-sevivio-el-fugodromo-en-santander-de-quilichao/

Hurtado, Teodora y Fernando Urrea. 2004. "Políticas y movimiento social negro agrario en el norte del Cauca”. En Gente negra en Colombia: dinámicas sociopolíticas en Cali y el Pacífico, editado por Olivier Barbary y Fernando Urrea, 359-396. Medellín: Lealon. 
Kidula, Jean Ngoya. 2006. "Ethnomusicology, the music canon, and African music: positions, tensions, and resolutions in the African academy”. Africa Today 52 (3): 99-113. https:// www.jstor.org/stable/4187723

Larraín, América y Pedro Madrid. 2018. "Música negra en los Andes colombianos. Historia y política de las sonoridades afro en Girardota-Antioquia”. Orfeu 3 (2): 10-24. https://doi. org/10.5965/2525530403022018010

Lora, Leonela. 2017. "Las fiestas de Adoración al Niño Dios en la vereda la Toma, Suárez, Cauca”. Tesis de pregrado en Antropología, Universidad del Cauca, Popayán.

Lucas, Maria Elizabeth. 2013. Introducción a Mixagens em campo: etnomusicologia, performance e diversidade cultural, editado por Maria Elizabeth Lucas, 11-14. Porto Alegre: Marcavisual.

Martínez, Óscar. 2017. "Música propia: una etnografía sobre una forma del pensamiento misak en el resguardo indígena de Guambía, en el sudoeste de Colombia”. Tesis de maestría, Instituto de Filosofia e Ciências Humanas, Programa de Pós-Graduação em Antropologia Social, Universidade Federal do Rio Grande do Sul, Porto Alegre. http://hdl.handle. net/10183/159144

Maya, Adriana y Raúl Cristancho. 2015. ¡Mandinga sea! África en Antioquia. Bogotá: Ediciones Uniandes.

Menezes, Rafael Jose de. 2014. "Esboço de uma teoria da música. Para além de uma antropologia sem música e de uma musicologia sem Homem”. Aceno 1 (1): 49-101. https://periodicoscientificos.ufmt.br/ojs/index.php/aceno/article/view/1800

Mina, Charo, Marilyn Machado, Patricia Botero Mosquera y Arturo Escobar. 2015. "Luchas del buen vivir por las mujeres negras del Alto Cauca”. Nómadas 43: 167-183. https:// doi.org/10.30578/nomadas.n43a10

Miñana, Carlos. 1997. "Los caminos del bambuco en el siglo XIX”. A Contratiempo 9: 7-11. http://www.musigrafia.org/acontratiempo/?ediciones/revista-9.html

Muñoz, Paloma. 2016. “Las almas de los violines 'negros””. Tesis doctoral en Antropología, Facultad de Ciencias Humanas y Sociales, Universidad del Cauca, Popayán.

Novak, David y Matt Sakakeenky. 2015. Introducción a Keywords in sound, editado por David Novak y Matt Sakakeenky, 1-11. Durham, NC: Duke University Press.

Palau, Paloma. 2010. "Bombarra, tuba y helicón: música de las Adoraciones del Niño Dios en el norte del Cauca y el sur del Valle”. En Músicas y prácticas sonoras en el Pacífico afrocolombiano, editado por Carolina Santamaría, Juan Sebastián Ochoa y Manuel Sevilla, 109-142. Bogotá: Editorial Universidad Javeriana.

—. 2019. "Fugas/jugas de afrocolombianos en el sur del valle del río Cauca”. MP4 video, 1:32 min., junio 24, https://youtu.be/34U4CCnRDgY

—. 2020. "Que sea para bien! Saberes musicales y alianzas sónicas de la gente negra del sur del valle del río Cauca, Colombia: una interpretación desde las (etno)musicologías”. Tesis de doctorado, Instituto de Artes, Programa de Pós-Graduação em Música, Universidade Federal do Rio Grande do Sul, Porto Alegre. http://hdl.handle.net/10183/214297 
Pardo, Mauricio. 2016. "Movimentos negros na região do Pacífico colombiano: organizações, violência e território”. Tesis doctoral, Programa de Pós-Graduação em Antropologia Social, Universidade Federal de Santa Catarina, Florianópolis.

Quijano, Aníbal. 2000. “Colonialidad del poder y clasificación social”. Journal of World-System Research 6 (2): 342-386. https://doi.org/10.5195/jwsr.2000.228

Quintero, Ángel. 2009. Cuerpo y cultura: las músicas mulatas y la subversión del baile. Madrid: Iberoamericana.

Rojas, Axel. 2016. "Estrategias de localización: desarrollo, capital y comunidades negras en la región norte del Cauca”. En Territórios de gente negra: processos, transformações e adaptações: ensaios sobre Colômbia e Brasil, editado por Antonio Pires, Flávio Gomes y Axel Rojas, 215-246. Cruz das Almas; Belo Horizonte: EDUFRB/Fino Traço.

Sandroni, Carlos y Michael Iyanaga. 2015. “Apresentação do dossiê Música e Festa”. Anthropológicas 26 (1): 1-14. https://periodicos.ufpe.br/revistas/revistaanthropologicas/article/ view/23914

Scott, James C. 2000. Los dominados y el arte de la resistencia: discursos ocultos. Ciudad de México: Ediciones Era.

Seeger, Anthony. 2015. Por que cantam os Kĩsêdjê: uma antropologia musical de um povo amazônico. São Paulo: Cosac Naify.

Sevilla, Manuel. 2009. “'No vengo a pedirte nada': la música en Villa Rica, Cauca, como un espacio donde se hace sociedad”. Revista Colombiana de Antropología 45 (2): 399-429. https:// doi.org/10.22380/2539472X.1005

Stein, Marília Raquel Albornoz. 2015. "Sonidos e imágenes en la construcción de la persona mbyà-guaraní en el sur de Brasil”. Anthropológica 33 (35): 205-233. http://revistas.pucp. edu.pe/index.php/anthropologica/article/view/14642/15228

Stengers, Isabelle. 2014. "La propuesta cosmopolítica”. Pléyade 14: 17-41. https://www.revistapleyade.cl/pleyade/ediciones/numero-14/

Stobart, Henry. 2008. The new (ethno)musicologies. Lanham: Scarecrow Press.

Titon, Jeff Todd. 2008. "Knowing fieldwork". En Shadows in the field: new perspectives for fieldwork in ethnomusicology, 2. ${ }^{\mathrm{a}}$ ed, editado por Gregory Barz y Timothy Cooley, 25-41. Oxford: Oxford University Press.

Turner, Victor y Edward Bruner. 1983. Anthropology of experience. Urbana; Chicago: University of Illinois.

Valencia García, Guadalupe. 2018. "Los recuerdos del porvenir y el porvenir de los recuerdos. Breves reflexiones sobre los usos del pasado". Revista de Estudios Sociales 65: 2-11. https://journals.openedition.org/revestudsoc/10106

Vanegas Muñoz, Gildardo y Axel Rojas. 2012. Poblaciones negras en el norte del Cauca: contexto político organizativo. Bogotá: Observatorio de Territorios Étnicos / Pontificia Universidad Javeriana.

Velasco Díaz, Carlos Alberto. 2016. "Violines, creatividades y resistencia afronortecaucana”. Páginas de Cultura 9 (11): 58-63. https://es.calameo.com/read/004341400e3e6d5e81c18 